\title{
Elastic-plastic analysis and shrinkage properties study of swelling rock borehole in coalmine
}

\author{
Jifeng Hou* and Zhongping Guo** \\ *College of Coal Engineering, Shanxi Datong University, Shanxi Datong 037003, China; College of Mining and Safety Engineering, Shandong \\ University of Science and Technology, Shandong Qingdao266590, China \\ **College of Mining and Safety Engineering, Shandong University of Science and Technology, Shandong Qingdao266590, China \\ *Corresponding Author: dtdxhjf@163.com
}

Submitted: 06/10/2018

Revised: $\quad 27 / 02 / 2020$

Accepted: $06 / 03 / 2020$

\begin{abstract}
The borehole shrinkage of swelling rock in coalmine is a complex problem affected by the combination of multiple fields, such as humidity field and stress field. By establishing the equilibrium equation of swelling rock borehole in coalmine, considering the expansion and softening properties, an elastic-plastic mechanics analysis was carried out, and the plastic zone radius and radial displacement of swelling rock borehole in coalmine were determined under the combination of humidity field and stress field. Taking the floor rock roadway in the 8\# coal seam of Songzao Coalmine in Chongqing as an example, the influence laws of water content, ground stress, and water pressure in the hole on the borehole shrinkage were studied. The results show that, with the increase of water content of the surrounding rock, the radius of plastic zone and radial displacement of borehole wall gradually increase. Both the humidity expansion and softening have an important influence on borehole shrinkage in coalmine, and the radial displacement of borehole wall under the combination of swelling and softening is greater than that of only considering expansion or softening. With the increase of ground stress, the radius of plastic zone and radial displacement of borehole wall gradually increase, showing a nonlinear increasing relation. The larger the water pressure in the borehole, the smaller the radius of plastic zone and radial displacement of borehole wall, and properly increasing the water pressure in the borehole can effectively control the borehole shrinkage. The accuracy of theoretical analysis was further verified by similar model tests. The results can provide a theoretical basis for solving the problem of borehole shrinkage in the swelling rock of coalmine.
\end{abstract}

Keywords: Swelling rock; Elastic-plastic analysis; Borehole shrinkage; Humidity stress field.

\section{INTRODUCTION}

Gas predrainage by drilling is one of the main measures to prevent gas accidents in coalmine (Liu et al., 2014, Lu et al., 2010, Liu et al., 2018). In the case of layer-through drilling and rock cross-cut coal uncovering, it frequently crosses the swelling rock. The swelling rock is soft rock that is easily weathered and softened. When the rock mass is disturbed, especially the change of environmental humidity and high ground stress conditions, the properties of the swelling rock will change greatly, resulting in volume swelling (Pi et al., 2018, Hawlader et al., 2005, Lu et al., 2016, Oldecop et al., 2012, Davison et al., 1990) and contraction (Yazdandoust et al., 2010, Estabragh et al., 2015). At present, coalmines generally adopt water-based gas control measures, such as coal seam water injection (Aguado et al., 2007), hydraulic fracturing (Liu et al., 2006), hydraulic flushing (Hao et al., 2016), and hydraulic slotting (Wang et al., 2017). When drilling into swelling rock strata, the swelling rock once affected by water expands and softens (Zhu et al., 2005, Vales et al., 2004, Yao et al., 2009), and the borehole diameter is reduced, which is easy to cause accidents such as holding the drill and clamping the drill. This seriously restricts the promotion and application of the hydraulic 
elimination measures in coalmines. Therefore, it is of great engineering significance to study the shrinkage properties of swelling rock borehole in coalmine under the combination effect of humidity field and stress field.

Miao et al. $(1993,1995,2002)$ studied the problem of the humidity stress field, established the humidity stress field theory and the combination equation, and analyzed the deformation problem of the surrounding rock of the roadway; Marco (2008) conducted a numerical simulation study on the expansion characteristics of tunnel surrounding rock, based on special triaxial tests; Butscher et al. (2011) studied the influence of tunnel excavation on regional groundwater flow and the influence of clay-sulphate expansion; Li et al. (2005) analyzed the humidification and shrinkage of swelling soils by humidity stress theory. These studies were mainly concentrated in tunnels, coalmine roadways and slopes, etc. However, there are relatively few studies devoted to the problem of swelling rock borehole shrinkage in coalmine, under the combination effect of humidity field and stress field.

By establishing the equilibrium equation of swelling rock borehole in coalmine, considering the expansion and softening properties, the elastic-plastic mechanics analysis was carried out in this paper, and the plastic zone radius and radial displacement of the surrounding rock of the swelling rock in coalmine were determined under the combination of humidity field and stress field. The theoretical analysis and similar model experiments were used to further study the effects of humidity, ground stress, and water pressure on the shrinkage properties of the borehole. The conclusions have certain guiding significance for solving the problem of borehole shrinkage of swelling rock in coalmine.

\section{ELASTIC-PLASTIC ANALYSIS OF SWELLING ROCK BOREHOLE}

To simplify the calculation, the following assumptions are made for the problem of borehole shrinkage of swelling rock in coalmine: (1) The borehole length of swelling rock is much longer than its diameter, and the force condition can be simplified to the plane strain problem. (2) The surrounding rock of the borehole is an ideal elastic-plastic material, and the stress-strain relationship is shown in Fig.1. (3) The compressive stress is positive, while the tensile stress is negative.

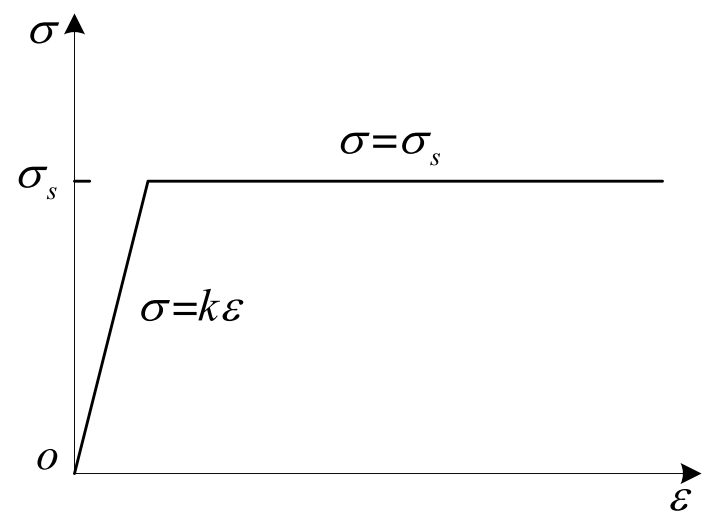

Fig. 1. Stress-strain diagram of ideal elastic-plastic material.

If the swelling rock mass is allowed to expand freely after absorbing water, it will produce a certain expansion strain. However, because of external load constraints and the deformation incongruity of internal mineral particles in swelling rock mass, the above expansion strain cannot occur freely, so the humidity expansion stress is generated.

A large number of studies have shown that there is a complex relationship between humidity swelling stress and water content, rock swelling coefficient, and so on. The study in Ding et al. (2007) showed that there is a hyperbolic relationship between humidity swelling stress $p_{\mathrm{s}}$ and water content $w$, and the expression was given by

$$
p_{\mathrm{s}}=\frac{\mathrm{E}}{1-2 \mu} \cdot \frac{\alpha w}{k_{1}+k_{2} w}
$$


where $k_{1}$ and $k_{2}$ are fitting parameters, $E$ and $\mu$ are elastic modulus and Poisson ratio, respectively, and $\alpha$ is humidity swelling coefficient.

This part of the stress is to generate additional strain, so that the total strain component is

$$
\varepsilon_{i j}=\frac{1+\mu}{E} \sigma_{i j}-\frac{\mu}{E} \delta_{i j} \sigma_{v}+\frac{\alpha \delta_{i j} w}{k_{1}+k_{2} w}
$$

This formula can also be written as follows:

$$
\sigma_{i j}=\frac{E}{1+\mu} \varepsilon_{i j}+\frac{\mu E}{(1+\mu)(1-2 \mu)} \delta_{i j} e-\frac{E \alpha \delta_{i j} w}{(1-2 \mu)\left(k_{1}+k_{2} w\right)}
$$

where $\varepsilon_{\mathrm{ij}}$ is the component of total strain; $\sigma_{\mathrm{ij}}$ is the component of total stress; $\sigma_{\mathrm{v}}$ is the total volume stress; $e$ is volume strain; $\delta_{i j}$ is Kronecker symbol.

$$
\sigma_{r}-\sigma_{\theta}+r \frac{\partial \sigma_{r}}{\partial r}=0
$$

Substituting equation (3) into the general elastic equilibrium equation (4), we obtain the equilibrium differential equation of the humidity stress field without considering the pore water pressure.

$$
\frac{\partial \sigma_{r}}{\partial r}+\frac{\sigma_{r}-\sigma_{\theta}}{r}+\frac{E \alpha}{1-2 \mu} \frac{\partial}{\partial r}\left(\frac{w}{\left(k_{1}+k_{2} w\right)}\right)=0
$$

where $\sigma_{r}$ is the component of radial stress, and $\sigma_{\theta}$ is the component of tangential stress.

Fig. 2 illustrates the force analysis of swelling rock borehole in coalmine.

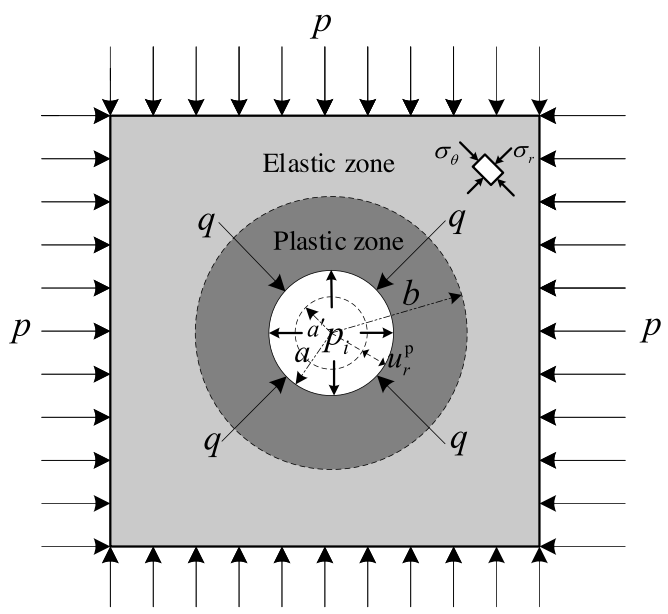

$p$-Ground stress field; $q$ - Humidity stress field; $p_{i}$ - Water pressure in the bore

$a$-Initial radius of borehole; $a^{\prime}$-Final radius of borehole under the combination of humidity field and in-situ stress field; $b$-Radius of plastic zone; $u_{r}^{\mathrm{p}}$-Radial displacement of plastic zone

Fig. 2. Force analysis of swelling rock borehole in coalmines. 
To conveniently discuss the problem, it is assumed that $w$ which is the average water content in the surrounding rock of the boreholes does not change with the radius $\mathrm{r}$, and the swelling pressure $p_{s}$ is constant by the formula (1). Therefore, the swelling pressure does not affect the stress distribution of the surrounding rock of the boreholes but only constitutes the stress boundary conditions.

And then the boundary conditions are given by

$$
\sigma_{r=a}=p_{i}+p_{s}, \sigma_{r \rightarrow \infty}=p
$$

The stress and displacement of the elastic zone $(b \leq r \leq \infty)$ of the surrounding rock can directly refer to the axisymmetric results of plane strain, which is

$$
\begin{aligned}
& \sigma_{r}^{e}=\left(1-\frac{b^{2}}{r^{2}}\right)\left(p+p_{s}\right)+\sigma_{b} \frac{b^{2}}{r^{2}} \\
& \sigma_{\theta}^{e}=\left(1+\frac{b^{2}}{r^{2}}\right)\left(p+p_{s}\right)-\sigma_{b} \frac{b^{2}}{r^{2}} \\
& u_{r}^{e}=\frac{1+\mu}{E}\left(p+p_{s}-\sigma_{b}\right) \frac{b^{2}}{r}+\frac{\alpha w}{\left(k_{1}+k_{2} w\right)} r
\end{aligned}
$$

For the plane strain problem and constant plastic zone volume, the axial stress $\sigma^{\mathrm{p}}{ }_{z}$ satisfies the following expression:

$$
\sigma_{z}^{\mathrm{p}}=\frac{\sigma_{\theta}^{\mathrm{p}}+\sigma_{r}^{\mathrm{p}}}{2}
$$

By equilibrium differential equation (5) and the boundary conditions $\left(\sigma_{r}\right)_{r=a}=p_{i}$, the stress field in plastic zone $(a \leq r \leq b)$ can be obtained as follows:

$$
\begin{aligned}
\sigma_{r}^{\mathrm{p}} & =\left(p_{i}+c \cot \varphi\right)\left(\frac{r}{b}\right)^{\frac{2}{\csc \varphi-1}}-c \cot \varphi \\
\sigma_{\theta}^{\mathrm{p}} & =\frac{\csc \varphi+1}{\csc \varphi-1}\left(p_{i}+c \cot \varphi\right)\left(\frac{r}{b}\right)^{\frac{2}{\csc \varphi-1}}-c \cot \varphi
\end{aligned}
$$

where $c$ is the cohesion, and $\varphi$ is the internal friction angle.

Given that $r=b$, we obtain $\sigma_{r}^{\mathrm{p}}=\sigma_{r}^{e}$ and ${\sigma^{\mathrm{p}}}_{\theta}=\sigma^{e}{ }_{\theta}$. Then the radius $b$ of the plastic zone and the radial stress $\sigma_{b}$ of the elastic-plastic interface can be deduced as follows:

$$
\begin{aligned}
& b=a\left[\frac{\left(p+p_{s}+c \cot \varphi\right)(1-\sin \varphi)}{p_{i}+c \cot \varphi}\right]^{\frac{c s c \varphi-1}{2}} \\
& \sigma_{b}=(1-\sin \varphi)\left(p+p_{s}\right)-c \cos \varphi
\end{aligned}
$$


To simplify the calculation, regardless of the dilatancy effect in the plastic zone of the surrounding rock, the nonassociative flow rule (Zheng et al., 2012) $\varepsilon^{\mathrm{p}}{ }_{r}+\varepsilon^{\mathrm{p}}{ }_{\theta}=0$ is used. By geometric equation and boundary conditions $r=b, u_{r}^{\mathrm{p}}=u_{r}{ }_{r}$, the radial displacement of borehole wall in swelling rock can be obtained as follows:

$$
u^{\mathrm{p}}{ }_{r}=\left(\frac{1+\mu}{E}\left(p+p_{s}-\sigma_{b}\right)+\frac{\alpha w}{\left(k_{1}+k_{2} w\right)}\right) \frac{b^{2}}{r}
$$

From equation (15), the radial displacement of the borehole wall $r=a$ is

$$
u_{r}^{\mathrm{p}}=\left(\frac{1+\mu}{E}\left(p+p_{s}-\sigma_{b}\right)+\frac{\alpha w}{\left(k_{1}+k_{2} w\right)}\right) \frac{b^{2}}{a}
$$

From the theoretical analysis, it is known that the factors affecting the boreholes deformation of the expansive rock in coalmines are complex, mainly including water content $w$, ground stress $p$, and water pressure in the hole.

\section{SHRINKAGE PROPERTIES ANALYSIS OF BOREHOLE UNDER HUMIDITY STRESS FIELD}

Taking the floor rock roadway in the $8 \#$ coal seam of Songzao Coalmine in Chongqing as the research background, $8 \#$ coal seam is relatively stable, the ground stress is about $15 \mathrm{MPa}$, the average thickness is $2.85 \mathrm{~m}$, the gas pressure is $1.79 \mathrm{MPa}$, and the gas content is $17.04 \mathrm{~m}^{3} / \mathrm{t}$. The top and bottom of the coal seam are relatively soft, mainly composed of expansive mudstone and sandy mudstone. It is easy to expand and soften when exposed to water.

According to the uniaxial compression test and direct shearing test, the mechanical parameters of mudstone samples with different water content were tested. The test results are shown in Table 1. From the elastic-plastic theory analysis, when the initial hole size of the boreholes is constant, water content, ground stress, and water pressure in the hole are the main factors, affecting the borehole shrinkage in swelling rock. This calculation analysis adopts a method of single factor analysis.

Table 1. Softening characteristics of borehole surrounding rock.

\begin{tabular}{cccccc}
\hline$w(\%)$ & $\mathbf{E}(\mathbf{G P a})$ & $\boldsymbol{\mu}$ & $\mathbf{C}(\mathbf{k P a})$ & $\boldsymbol{\varphi ( \mathbf { d e g } )}$ & $\boldsymbol{\alpha}$ \\
\hline 0 & 4.03 & 0.22 & 3532 & 40.80 & \\
3.2 & 3.22 & 0.23 & 2035 & 34.01 & \\
7.5 & 2.78 & 0.26 & 2680 & 29.63 & \\
11.2 & 2.56 & 0.28 & 2527 & 27.57 & \\
15.2 & 2.42 & 0.30 & 2416 & 26.01 & \\
17.8 & 2.39 & 0.31 & 2365 & 25.58 & \\
\hline
\end{tabular}

\section{Influence of the water content on the borehole shrinkage}

To study the influence of humidity on the borehole shrinkage, the water content of the surrounding rock in the calculation is $0,3.2 \%, 7.5 \%, 11.2 \%, 15.2 \%$, and $17.8 \%$, respectively. The calculation results are shown in Fig. 3 . 


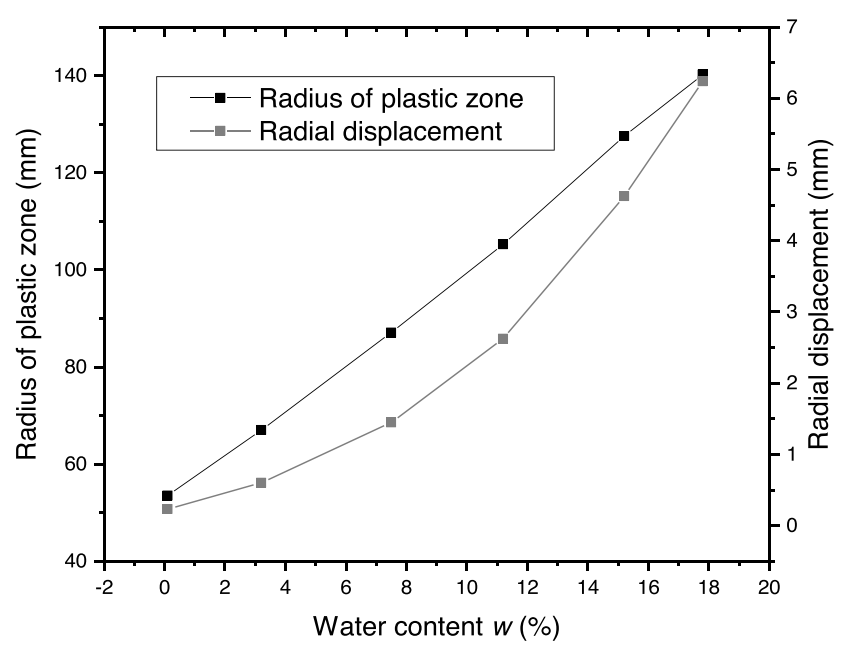

Fig. 3. Influence of the water content on the borehole shrinkage.

From Fig. 3 it can be observed that, with the increase of water content of the surrounding rock, the radius of plastic zone and radial displacement of borehole wall gradually increase. For example, when the water content increases from 0 to saturation (17.8\%), the radius of the plastic zone of the borehole increases from $53.52 \mathrm{~mm}$ to $140.23 \mathrm{~mm}$, while the radial displacement of borehole wall increases from $0.23 \mathrm{~mm}$ to $6.24 \mathrm{~mm}$. It can be seen that the water content has an important influence on the mechanical response of the swelling rock boreholes. Reducing the water content of the surrounding rock within a certain range will help reduce the radius of the plastic zone and the radial displacement of borehole wall.

Fig. 4 shows the shrinkage characteristics of the swelling rock borehole under three different conditions, namely, 1) only considering the humidity expansion effect; 2) only considering the humidity softening effect; 3) considering the humidity expansion and softening effects.

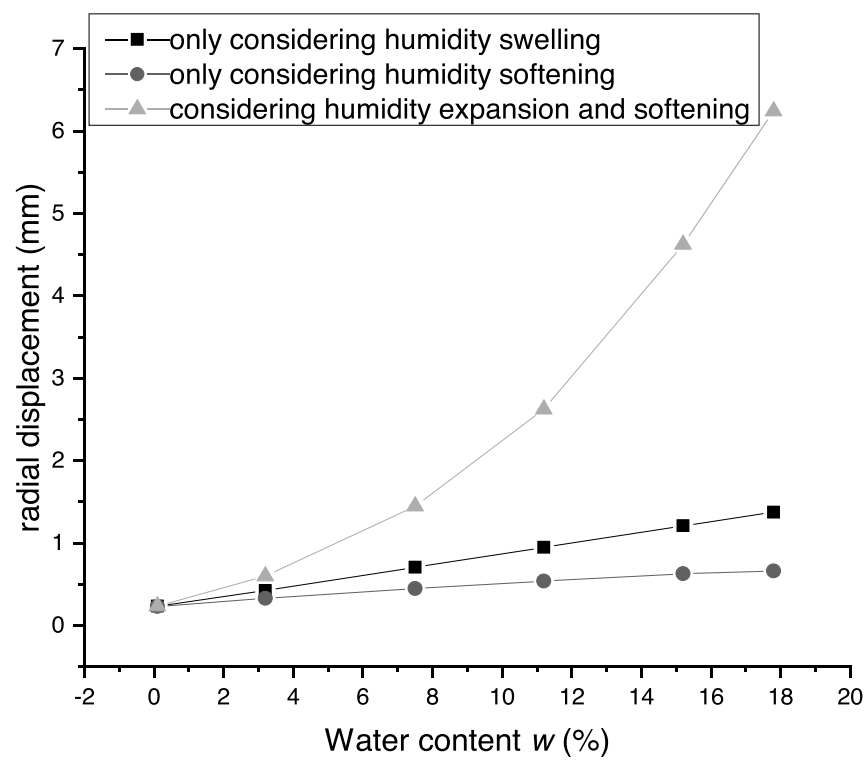

Fig. 4. Shrinkage characteristics of the swelling rock boreholes for different situations. 
It can be seen from Fig. 4 that the influence of radial displacement of borehole wall in swelling rock under the combination of humidity swelling and softening is greater than that of only considering swelling or softening. The radial displacement of borehole wall under combination is $6.24 \mathrm{~mm}$; the radial displacement of borehole wall is $1.37 \mathrm{~mm}$ only considering the humidity swelling, while the radial displacement of borehole wall is $0.65 \mathrm{~mm}$ only considering the humidity softening.

Therefore, for swelling rock borehole in coalmine, in addition to considering the swelling deformation of the swelling rock, it is also necessary to pay more attention to the influence of water immersion on the softening of the swelling rock.

\section{Influence of the ground stress on the borehole shrinkage}

In order to study the influence of ground stress on the borehole shrinkage, the ground stress in the calculation is 5 $\mathrm{MPa}, 10 \mathrm{MPa}, 15 \mathrm{MPa}, 20 \mathrm{MPa}, 25 \mathrm{MPa}$, and $30 \mathrm{MPa}$, respectively. The calculation results are shown in Fig. 5.

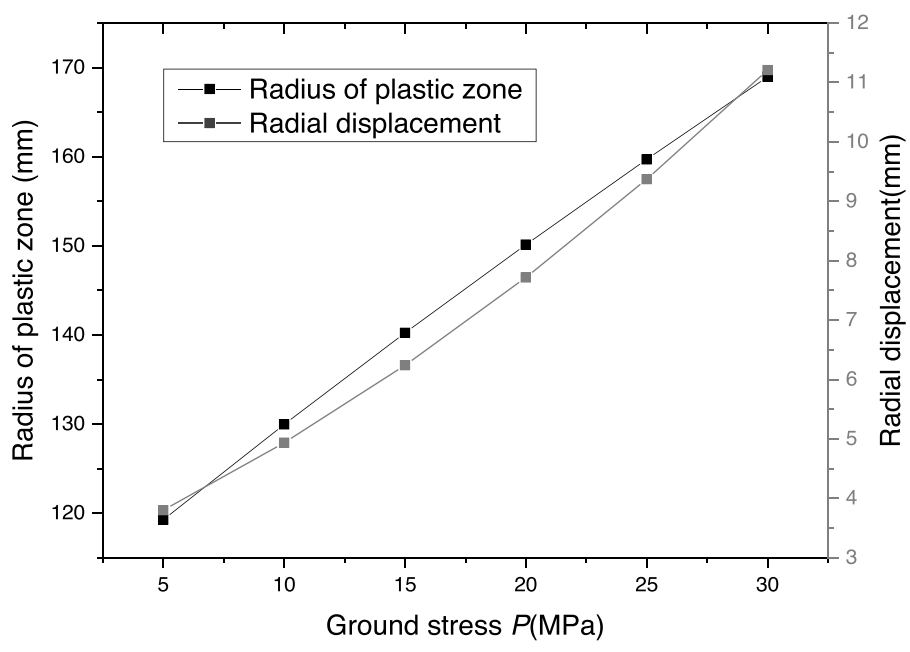

Fig. 5. Influence of ground stress on the borehole shrinkage.

From Fig. 5, it can be easily found that, with the increase of the ground stress, the radius of plastic zone of the borehole and the radial displacement of borehole wall also increase, which is a nonlinear increasing relationship. The radius of plastic zone of the surrounding rock and the radial displacement of borehole wall increased from $119.25 \mathrm{~mm}$ and $3.80 \mathrm{~mm}$ at $5 \mathrm{MPa}$ to $168.96 \mathrm{~mm}$ and $11.20 \mathrm{~mm}$ at $30 \mathrm{MPa}$, respectively. Consequently, the ground stress gradually increases with the depth of coal mining increasing, and the boreholes shrinkage in coalmines swelling rock becomes more and more serious, which should be taken seriously.

Based on Fig. 5, Fig. 6 shows the relation curves between the borehole shrinkage and ground stress under different water content. 


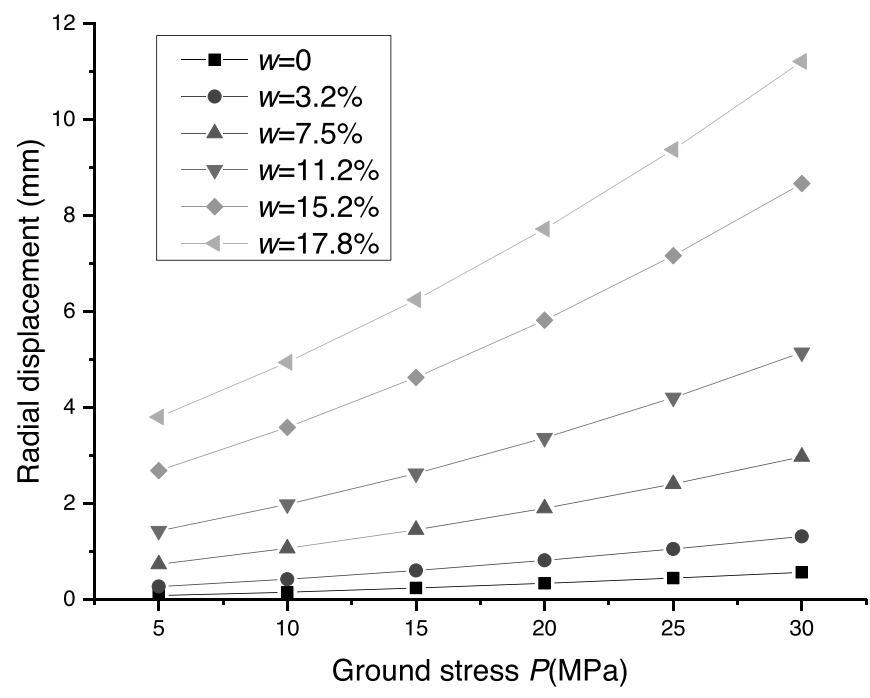

Fig. 6. Relation between borehole shrinkage and ground stress under different water content.

As shown in Fig. 6, it is observed that, with the increase of water content, the influence of ground stress on the borehole shrinkage of the swelling rock is more significant. Mainly due to the increase of water content, the lithology of the swelling rock will become soft, and its strength will decrease. For example, when the water content is 0 , the radial displacement of borehole wall increases from $0.078 \mathrm{~mm}$ at $5 \mathrm{MPa}$ to $0.56 \mathrm{~mm}$ at $30 \mathrm{MPa}$, while the radial displacement of borehole wall increases from $3.80 \mathrm{~mm}$ at $5 \mathrm{MPa}$ to $11.20 \mathrm{~mm}$ at $30 \mathrm{MPa}$, when the water content is $17.8 \%$. Consequently, the presence of water exacerbates the influence of ground stress on the borehole shrinkage of the swelling rock in coalmine, which should be taken seriously.

\section{Influence of the water pressure on the borehole shrinkage}

To study the influence of water pressure on the borehole shrinkage, the water pressure in the boreholes is, respectively, $0 \mathrm{MPa}, 3 \mathrm{MPa}, 6 \mathrm{MPa}, 9 \mathrm{MPa}, 12 \mathrm{MPa}$, and $15 \mathrm{MPa}$. The calculation results are shown in Fig. 7.

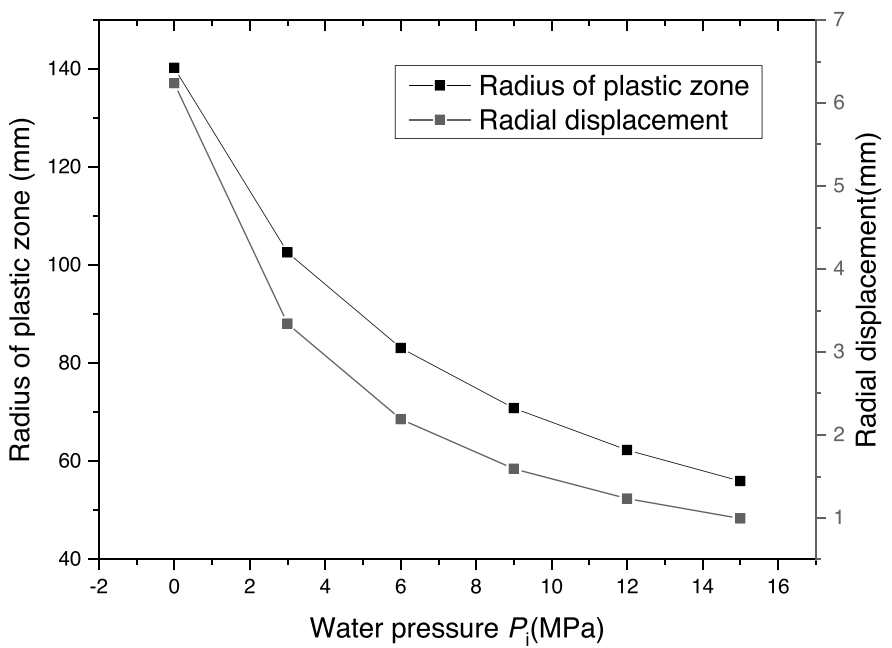

Fig. 7. Influence of the water pressure on the borehole shrinkage. 
As shown in Fig. 7, it is indicated that the water pressure in the borehole has an extremely important influence on the radius of plastic zone of the surrounding rock of the expansive rock and the radial displacement of borehole wall. The radial displacement of borehole wall decreases with the increase of the water pressure in the boreholes. The radius of plastic zone and radial displacement of borehole wall increased from $140.24 \mathrm{~mm}$ and $6.24 \mathrm{~mm}$ at $0 \mathrm{MPa}$ to $55.98 \mathrm{~mm}$ and $1.0 \mathrm{~mm}$ at $15 \mathrm{MPa}$, respectively. It can be seen that increasing the water pressure in the borehole can effectively control the shrinkage deformation of swelling rock.

Based on Fig. 7, Fig. 8 shows the relation curves between the borehole deformation and water pressure pi under different ground stresses.

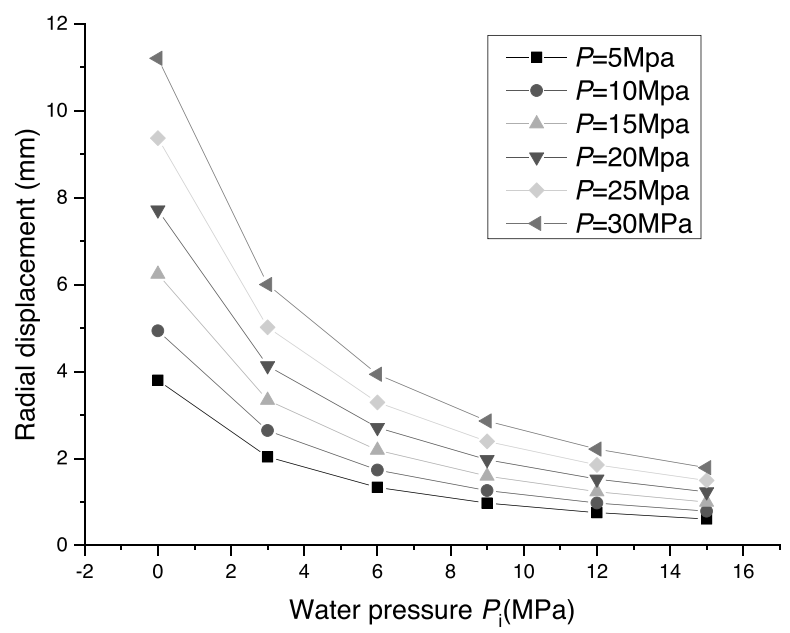

Fig. 8. Relation between borehole shrinkage and $p_{i}$ under different ground stress.

It can be seen from Fig. 8 that, under different ground stress conditions, the influence of water pressure in the borehole on the radius of plastic zone and radial displacement of borehole wall of swelling rock borehole is different. When the ground stress is large, increasing the water pressure in the boreholes can significantly reduce the radial displacement value of the borehole wall. The radial displacement value of the borehole wall decreases from $11.20 \mathrm{~mm}$ at $0 \mathrm{MPa}$ to $1.78 \mathrm{~mm}$ at $30 \mathrm{MPa}$, which decreases about $80 \%$. Thus, increasing the water pressure in the boreholes can effectively control boreholes shrinkage in swelling rock. Especially when the ground stress is at a high level, increasing the water pressure in the boreholes is particularly significant for controlling boreholes shrinkage.

\section{SIMILAR MODEL EXPERIMENTS Experimental equipment and samples}

The experiment was carried out on a high-temperature triaxial test machine. As shown in Fig. 9, the test machine was mainly composed of four parts: (1) axial pressure and confining pressure servo system; (2) triaxial chamber heating and insulation system; (3) water supply system; (4) data acquisition system. 

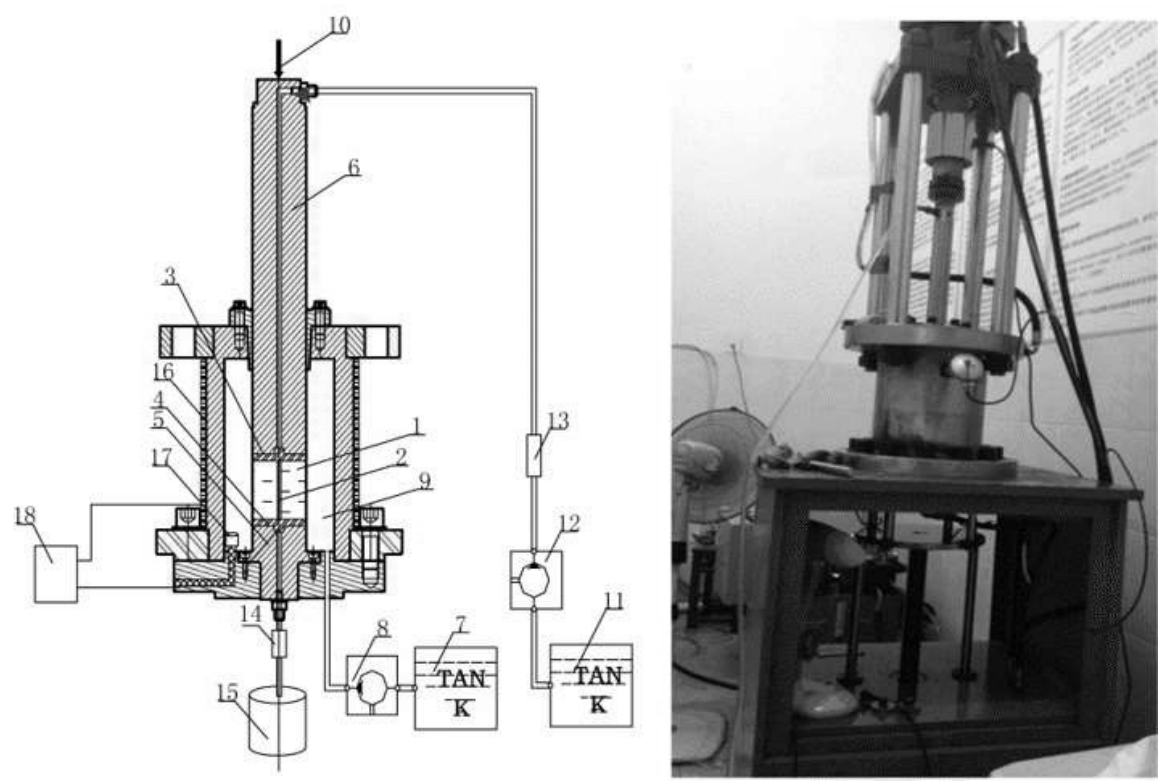

1- mudstone test specimen; 2-passing water hole; 3-upper head; 4-down head; 5-pressure seat; 6-pressure bar; 7-oil cylinder; 8-double servo hydraulic station; 9- confining pressure chamber; 10-axis pressure; 11-water tank; 12-water pump; 13-flow meter; 14-relieving valve; 15-water container;16-silicone rubber heating belt; 17- temperature sensor;

18-temperature microcontroller

Fig. 9. The high temperature triaxial test machine.

The mudstone samples were taken from Chongqing Songzao Coalmine. It is gray, dense, crack-free and does not disintegrate when it is in contact with water. According to the international rock mudstone sample size, cylindrical specimens were machined with a diameter of $50 \mathrm{~mm}$ and a height of $50 \mathrm{~mm}$. The machining accuracy is in accordance with the rock test standard. (In the height of the sample, the diameter error should not exceed $0.3 \mathrm{~mm}$. The maximum unevenness of both ends should not exceed $0.05 \mathrm{~mm}$. The end face should be perpendicular to the axis of the sample and the maximum deviation should not exceed $0.25^{\circ}$.) The borehole was drilled with a dry drill, the mudstone samples were not damaged, and the borehole diameter is $10 \mathrm{~mm}$ as shown in Fig. 10.

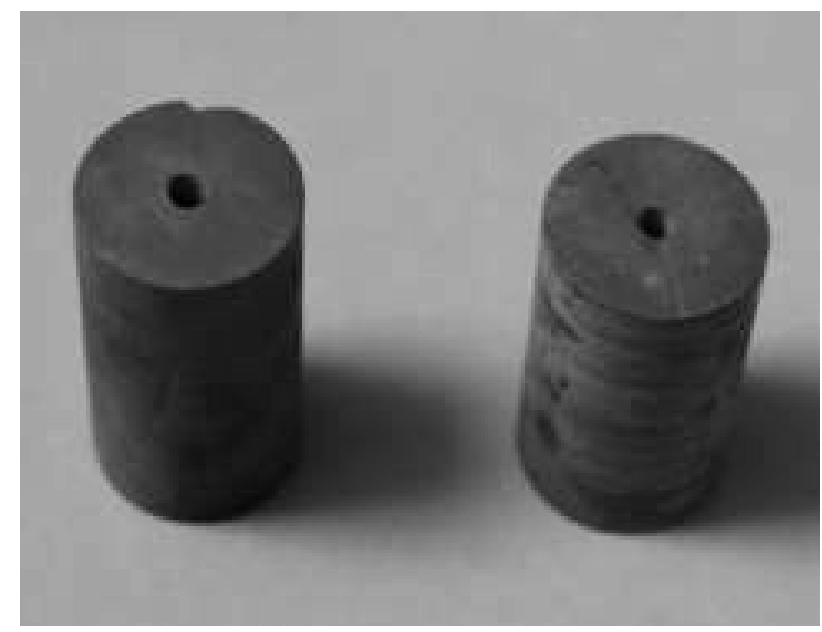

Fig. 10. The mudstone specimens (boreholes $\varphi 10 \mathrm{~mm}$ ). 


\section{Experimental design}

To really simulate the borehole shrinkage of the swelling rock in coalmines under the combination of humidity field and ground stress field, water was drilled into the center boreholes of the mudstone samples, and a certain axial compression and confining pressure were applied to the mudstone samples in this experiment. Due to the limitation of experimental conditions, ground stress is constant in the experiment, and only the influence of humidity change on boreholes shrinkage was studied.

Test steps are as follows: 1) Pressure-holding loading method is adopted in the test, and the axial pressure is equal to the confining pressure $(25 \mathrm{MPa})$. The pressure of $0.01 \mathrm{MPa}$ was applied to the mudstone sample in the axial direction so that the mudstone rock sample was strained to zero in the axial direction, and a certain confining pressure was applied to the mudstone sample from the surroundings to simulate the ground stress, and the loading was set to the setting pressure, as shown in Figure 11.2) Water flowed out of the central borehole. The water passing time was taken for $1 \mathrm{~h}, 2 \mathrm{~h}, 3 \mathrm{~h}, 5 \mathrm{~h}$, and $8 \mathrm{~h}$, respectively. 3) When the radial strain of the outer diameter of the sample tends to be stable, the water content of the mudstone was measured at the end of the experiment. 4) The diameter D'=2a' of the central hole after experiment was measured by pouring gypsum slurry into the hole.

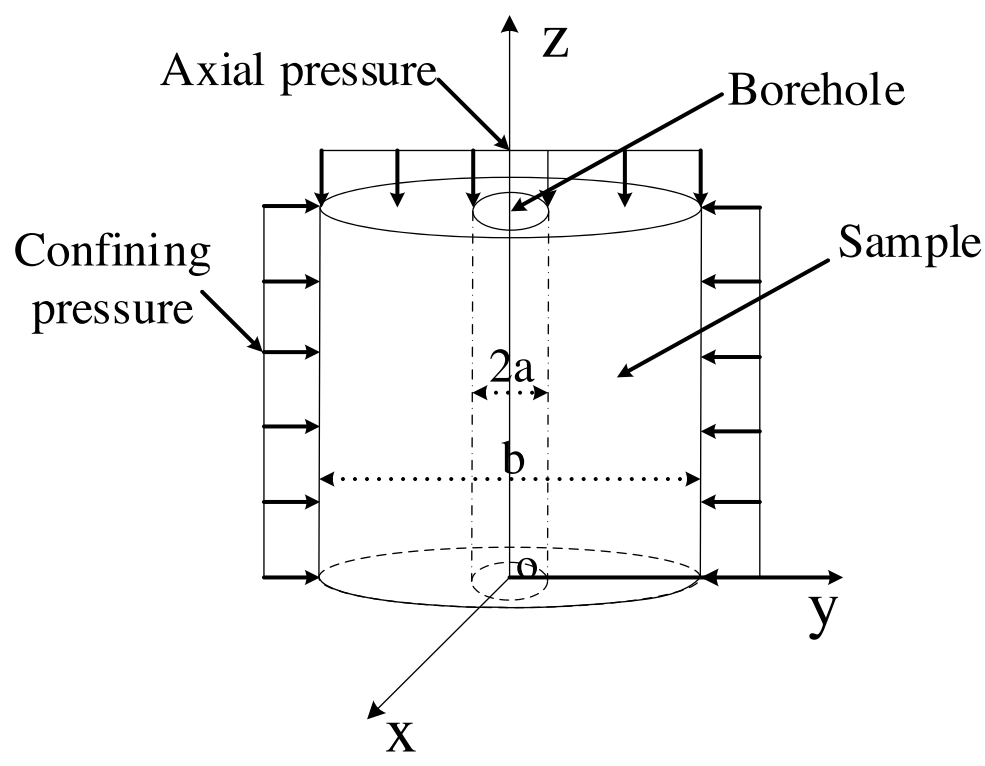

Fig. 11. Schematic diagram of borehole shrinkage.

\section{Experimental results and analysis}

(1) Experimental results

After the experiment, the diameter $\mathrm{D}^{\prime}=2 \mathrm{a}^{\prime}$ of the central borehole was measured. The experimental results are shown in Table 2. 
Table 2. Experimental results of borehole shrinkage under different water content.

\begin{tabular}{|c|c|c|c|c|c|}
\hline Samples number & 1\# & 2\# & 3\# & 4\# & $5 \#$ \\
\hline Water content $w$ & $4.2 \%$ & $8.7 \%$ & $12.2 \%$ & $15.7 \%$ & $17.8 \%$ \\
\hline $\mathrm{D}=\mathbf{2 a}(\mathbf{m m})$ & 10.02 & 10.00 & 10.02 & 10.04 & 10.02 \\
\hline $\mathbf{D}>=\mathbf{2} \mathbf{a}>(\mathbf{m m})$ & 9.70 & 9.32 & 8.86 & 8.48 & 7.90 \\
\hline Radial displacement(mm) & 0.16 & 0.34 & 0.58 & 0.78 & 1.06 \\
\hline
\end{tabular}

(2) Comparative analysis of experimental and theoretical results

As shown in Table 2 and Fig. 12, it is observed that, with the increase of water content, the radial displacement of the central borehole wall increases significantly under constant stress conditions. This is basically consistent with the law of theoretical analysis.

In addition, Fig. 12 indicates that the theoretical solution of the maximum radial displacement of the borehole wall is close to the experimental value, and the deviation is between $5 \%-10 \%$. The deviation is relatively small, within the permitted range. It proves the accuracy and reliability of theoretical analysis. Consequently, the elastic-plastic displacement solution of the swelling rock in coalmines is in line with the actual project, and it can fully reflect the shrinkage deformation law of swelling rock boreholes in coalmines under the combination action of humidity and stress field.

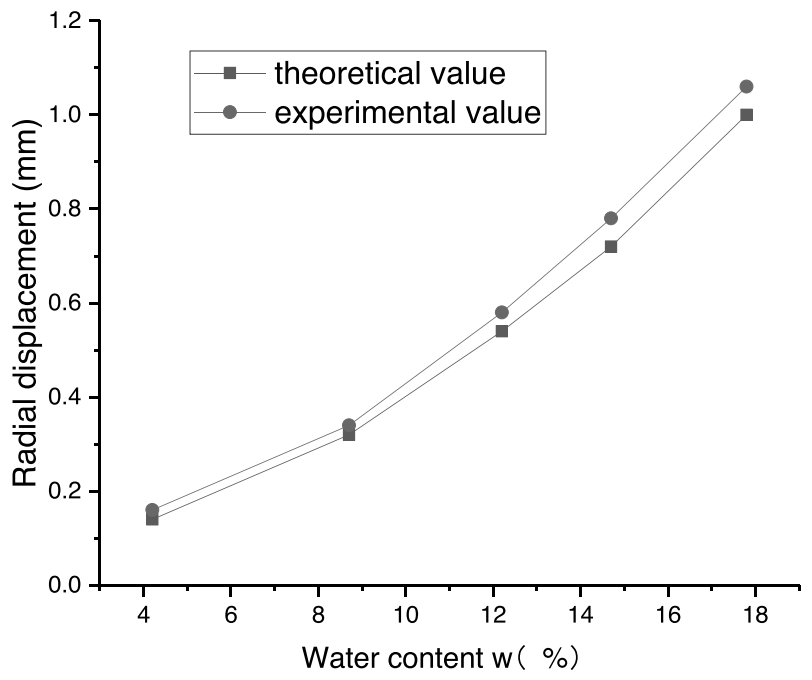

Fig. 12. The comparison between experimental and theoretical results.

(3) Discussion

We have shown that the elastic-plastic displacement solution of swelling rock borehole established by the theory of humidity stress field and elastic-plastic mechanics, considering the characteristics of expansion and softening, is highly consistent with the test curve. The influence of water content, ground stress, and water pressure in the hole on the borehole shrinkage was discussed by theoretical analysis and similar model experiments. We found that the water content and ground stress have significant effects on the borehole shrinkage of swelling rock, and the water pressure in the borehole has a certain inhibition on the borehole shrinkage of swelling rock. By comparing the effect of expansion and softening on the shrinkage deformation of swelling rock in coalmine, it has been found that the displacement 
of borehole wall under the combination action is greater than that under the simple consideration of expansion or softening.

The main contribution of this paper is that the elastic-plastic displacement equation of coalmine swelling rock borehole considering the combination effect of humidity field and stress field was established, based on the theory of humidity stress field and elastic-plastic mechanics. The elastic-plastic displacement equation is expected to promote mining development in the following aspects: a) Understanding the stress-strain relationship and deformation characteristics of swelling rock borehole under the combination effect of humidity field and stress field; b) providing an accurate displacement equation for the deformation analysis of coalmine swelling rock borehole considering the combination effect of humidity field and stress field; c) providing a theoretical basis for solving the problem of shrinkage and sticking of the swelling rock in coalmine.

The biggest limitation of this paper is neglecting the change of water content with radius $r$, to simplify the calculation. This has some deviation from the actual situation. The next step is to study the variation of water content in the surrounding rock with radius $r$.

\section{CONCLUSIONS}

Based on the theory of humidity stress field and elastic-plastic mechanics, the equilibrium equation for boreholes in swelling rock was established in this paper, and then the analytical expression of elastic-plastic displacement considering the effects of humidity swelling and softening was derived. It has certain value for theoretical research and engineering applications. In this paper, the influences of humidity field, ground stress field, and water pressure on the borehole shrinkage of the swelling rock were studied by the theoretical analysis and similar model experiments. Some important conclusions can be summarized as follows:

1. With the increase of water content of the surrounding rock, the radius of plastic zone and radial displacement of borehole wall gradually increase. Both the humidity expansion and softening have an important influence on boreholes shrinkage in coalmines, and the radial displacement of borehole wall under the combination of swelling and softening is greater than that of only considering expansion or softening.

2. With the increase of the ground stress, the radius of plastic zone and radial displacement of borehole wall gradually increase, showing a nonlinear increasing relation. The presence of water exacerbates the influence of ground stress on the borehole shrinkage of the swelling rock in coalmine, which should be taken seriously.

3. The larger the water pressure in the boreholes, the smaller the radius of plastic zone and radial displacement of borehole walls, and properly increasing the water pressure in the boreholes can effectively control the boreholes shrinkage.

Therefore, besides the initial ground stress field, the swelling and softening effects of water on swelling rock should be taken into account in deep coalmine.

\section{ACKNOWLEDGMENT}

This work was supported by National Natural Science Foundation of China (Grant No. 51304127).

\section{REFERENCES}

Aguado, M.B.D. \& Nicieza, C.G. 2007. Control and prevention of gas outbursts in coal mines, Riosa-Olloniego coalfield, Spain. International Journal of Coal Geology, 69(4): 253-266.

Butscher, C., Huggenberger, P. \& Zechner, E. 2011. Impact of tunneling on regional groundwater flow and implications for swelling of clay-sulfate rocks. Engineering Geology, 117(3): 198-206.

Davison, L.R. \& Atkinson, J.H. 1990. Continuous loading Oedometer Testing of Soils. Quarterly Journal of Engineering Geology, London, 23:347-355. 
Ding, Z.Z., Zheng, Y.R. \& Li, L.S. 2007. Trial study on variation regularity of swelling force. Rock and Soil Mechanics, 28(7): 1328-1332.

Estabragh, A.R., Parsaei, B. \& Javadi, A.A. 2015. Laboratory investigation of the effect of cyclic wetting and drying on the behaviour of an expansive soil. Soils and Foundations, 55(2): 304-314.

Hawlader, B.C., Lo, K.Y. \& Moore, I.D. 2005. Analysis of tunnels in shaly rock considering three-dimensional stress effects on swelling. Canadian Geotechnical Journal, 42(1): 1-12.

Hao, F.C., Sun, L.J. \& Zuo, W.Q. 2016. Hydraulic flushing aperture variation and anti-blocking technology considering rheological property. Journal of China Coal Society, 41(6): 1434-1440.

Li, K.Q. \& Zhou, Z.G. 2005. Deformation analysis of expansive soils induced by increased humidity based on the theory of humidity stress field[J]. Journal of Changsha University of Science and Technology, 2(4): 2-6.

Liu, J.X., Li, Z.Q. \& Li, S.H. 2006. Protection against outburst mechanism of hydraulic extrusion measure in the front of coal road heading face. Journal of China Coal Society, 31(2):183-186.

Liu, Q.Q., Cheng, Y.P., Yuan, L., Fang, Y.X., Shi, D.Z. \& Kong, S.L. 2014. A new effective method and new materials for high sealing performance of cross-measure CMM drainage boreholes. Journal of Natural Gas Science \& Engineering, 21:805813.

Liu, C.W., Xia, B.W. \& Lu, Y.U. 2018. Coal bed Methane Extraction Using the Self-Oscillating Water Jet Slotting Method. Energies, 11(4): 897.

Lu, Y.U., Liu, Y., Li, X.H. \& Kang, Y. 2010. A new method of drilling long boreholes in low permeability coal by improving its permeability. International Journal of Coal Geology, 84(2): 94-102.

Lu, Y.U., Ao, X., Tang, J.R., Jia, Y.Z., Zhang, X.W. \& Chen, Y.T. 2016. Swelling of shale in supercritical carbon dioxide. Journal of Natural Gas Science \& Engineering, 30(4): 268-275

Marco, B. 2008. Numerical simulation of the swelling behaviour around tunnels based on special triaxial tests. Tunnelling and Underground Space Technology, 23(5): 508-521.

Miao, X.X., Yang, C.Y. \& Chen, Z.D. 1993. Humidity stress field theory in swelling rock mass. Rock and Soil Mechanics,14(4): 49-55.

Miao, X.X. 1995. Large deformation analysis of surrounding rock of a tunnel in swelling rock mass based on the humidity stress field theory. Journal of China University of Mining \& Technology, 24(1): 58-63.

Miao, X.X., Mao, X.B. \& Lu, A.H. 2002. Application of the humidity stress field theory to the soft surrounding rock stability control around coal mining roadway. Ground Pressure and Strata Control, 3:1-5.

Oldecop, L. \& Alonso, E. 2012. Modelling the degradation and swelling of clayey rocks bearing calcium-sulphate. International Journal of Rock Mechanics and Mining Sciences, 54(22): 90-102.

Pi, J., Wang, X.G., Cao, R.L., Zhao, Y.F. \& Huang, X. 2018. Innovative loading system for applying internal pressure to a test model of pre-stressed concrete lining in pressure tunnels. Journal of Engineering Research, 6(2): 24-45.

Vales, F., Minh, D.N., Gharbi, H. \& Rejeb, A. 2004. Experimental study of the influence of the degree of saturation on physical and mechanical properties in tournemire shale (France). Applied clay science, 26(1/4):197-207.

Wang, H.Y., Xia, B.W., Lu, Y.Y. \& Gong, T. 2017. Study on the propagation laws of hydrofractures meeting a faulted structure in the coal seam. Energies, 10(5):654.

Yao, Q.L., Zhang, F. T., Ding, X. L., Zhang, L. \& Jiang, G. 2009. Experimental research on instability mechanism of silty mudstone roofs under action of water and its application. Procedia Earth and Planetary Science, 1(1):402-408.

Yazdandoust, F. \& Yasrobi, S.S. 2010. Effect of cyclic wetting and drying on swelling behavior of polymer- stabilized swelling clays. Applied Clay Science, 50(4): 461-468.

Zhu, Z.D., Zhang, A. J. \& Xing, F.D. 2005. Research on swelling and strain softening model of swelling rock in hongshanyao. Chinese Journal of Rock Mechanics and Engineering, 24(3):389-393.

Zheng, X.G., Ji, M. \& Zhang, N. 2012. Rheological model of swelling rock considering humidity effect. Journal of China Coal Society, 37(3): 396-401. 